\title{
Reinforcer effectiveness in dogs-The influence of quantity and quality
}

\author{
Stefanie Riemer ${ }^{\mathrm{a}, \mathrm{b}}$, Sarah L.H. Ellis ${ }^{\mathrm{b}}$, Hannah Thompson ${ }^{\mathrm{b}}$, Oliver H.P. Burman ${ }^{\mathrm{b}, *}$ \\ a Division of Animal Welfare, Vetsuisse Faculty, University of Bern, Switzerland \\ ${ }^{\mathrm{b}}$ School of Life Sciences, University of Lincoln, UK
}

\section{A R T I C L E I N F O}

\section{Keywords:}

Reinforcer effectiveness

Reinforcer quantity and quality

Reward

Preference testing

Contrast effect

Domestic dog Canis familiaris

\begin{abstract}
A B S T R A C T
Reinforcer effectiveness refers to the reinforcer's ability to control the subject's target behaviour and is therefore critical to training success. Yet animals' preferences, and the effectiveness of different rewards to function as reinforcers, are often assumed without scientific investigation. Here we explored the influence of reward quality, quantity and changes in reward value on motivation in domestic dogs. Subjects were trained to traverse a runway for a food reward. In Study 1, the quantity of food was varied (1 vs 5 pieces of dry food), while in Study 2 , food quality was varied (1 piece of sausage vs 1 piece of dry food). Dogs were tested in two conditions (counterbalanced). In the unshifted condition, they received the low value reward in all of ten trials; in the shifted condition, reward value was altered (high value: trials 1-4 and 9-10; low value: trials 5-8). While preliminary preference tests had confirmed the relative value of the presumed high and low value rewards for both quantity and quality, dogs' responses in the runway task differed between the quality and quantity studies. Dogs ran significantly faster for the higher quality food compared to the lower quality food, confirming greater reinforcer effectiveness of the preferred food type. In contrast, there was no significant effect of food quantity on running speed at any stage. Higher quality rewards therefore appear to entail greater incentive motivation in dogs than a greater quantity of a lower value reward, with reward-specific habituation needing to be considered.
\end{abstract}

\section{Introduction}

Recent decades have seen a move towards the use of positive reinforcement in animal training, including training of companion and working dogs (Arhant et al., 2010; Haverbeke et al., 2010; Fukuzawa and Hayashi, 2013; Vicars et al., 2014), zoo animals (Desmond and Laule, 1994), laboratory animals (Perlman et al., 2012), and farm animals (Manteuffel et al., 2009). A number of benefits of training using positive reinforcement ("target behavior is increased subsequent to the presentation of a (presumably subjectively pleasant) stimulus", Blackwell et al., 2008) compared to techniques such as positive punishment (presentation of an aversive stimulus leading to a reduction in the target behaviour) or negative reinforcement (removal of an aversive stimulus leading to an increase in the target behaviour, Blackwell et al., 2008) have been suggested. These include (a) improved welfare as indicated by fewer behavioural indicators of stress (Schilder and van der Borg, 2004; Perlman et al., 2012; Deldalle and Gaunet, 2014), (b) improved husbandry and handling, with a reduction of intra- and interspecific aggression such as that towards keepers (Desmond and Laule, 1994), (c) fewer behavioural problems including aggression, fear and stereotypies (Hiby et al., 2004; Blackwell et al., 2008; Herron et al., 2009; Perlman et al., 2012), (d) use as an enrichment technique in captive situations (Desmond and Laule, 1994; Manteuffel et al., 2009), (e) better obedience (Hiby et al., 2004; Haverbeke et al., 2008), and (f) improved quality, efficiency and reduced cost of data collection for scientific studies (Desmond and Laule, 1994; Perlman et al., 2012). However, positive reinforcement training can only be effective if subjects 'like', and are motivated to obtain (i.e. 'want', Berridge, 2000) the response-contingent stimuli used to strengthen future behaviour. Assuming that these stimuli maintain or increase the frequency of behaviour that they follow, they are called positive reinforcers (Schultz, 2015; Stephens et al., 2010).

Reinforcer effectiveness refers to the reinforcer's ability to control the subject's target behaviour (other than simple consumption) (Gaalema et al., 2011) and is therefore critical to the success of training. Yet individuals' preferences and reinforcer effectiveness are often assumed without scientific investigation (but see Vicars et al., 2014), and these assumptions may not always be appropriate. For example, evidence from captive exotic animals suggests that caregiver ratings are not necessarily accurate in predicting subjects' preferences for different food rewards (Gaalema et al., 2011). In the interest of ensuring effective training whilst also safeguarding subjects' welfare (e.g. avoiding food or water deprivation in an attempt to increase animals' motivation to participate in operant paradigms for food or water reinforcement),

\footnotetext{
* Corresponding author at: School of Life Sciences, University of Lincoln, Joseph Banks Laboratories, Beevor Street, Lincoln LN6 7DL, UK.

E-mail address: oburman@lincoln.ac.uk (O.H.P. Burman).
} 
preferences and reinforcer effectiveness of different types and magnitudes should therefore be established.

Reinforcement value can be altered either by a change in quantity (Crespi, 1942; Maxwell et al., 1976; Rashotte, 1979; Goomas, 1981; Binkley et al., 2014) or by using a reward of different quality (Elliott, 1928; Tinklepaugh, 1928; Boyer and Swank, 1980; Pellegrini and Mustaca, 2000; Freidin et al., 2009), and animals may respond differently to qualitative and quantitative reinforcer variation (e.g. Lowe et al., 1974; but see Hutt, 1954). Surprisingly, there appears to be a lack of studies comparing differential effects of variation in quality vs quantity of reinforcers directly (but see Miller, 1976). Moreover, in the few studies that have attempted to investigate this question, the socalled qualitative differences primarily refer to foods or liquids that differ only in concentration, rather than to different types of rewards (e.g. Bonem and Crossman, 1988; Marx and Tombaugh, 1970; Schaeffer and Hanna, 1966; Taylor, 1977).

Classic models assumed that an animal's response strength in operant tasks, typically measured in terms of rate, speed, latency, and choice, was directly related to the magnitude (i.e. "quantity, intensity, or duration", Trosclair-Lasserre et al., 2008;) of the reward provided (see e.g. Herrnstein, 1970; reviewed by Collier et al., 1986; Flaherty, 1999). In view of animals' apparently emotional reactions to unexpected changes in reinforcer quantity or quality, these interpretations have later been modified to include an effect of reinforcer value on incentive motivation (i.e. appetitive motivation or 'wanting', after Berridge and Robinson, 1995) rather than influencing behaviour directly (see Flaherty, 1999). Thus, the value of a particular reward to a given individual is not static, but changeable depending on the internal state at the time it is encountered and the individual's previous experience of that reward (Schultz et al., 1997). The same rewards do not necessarily elicit the same response from different individuals, or from the same individual at different time points (e.g. Killeen and Jacobs, 2016), and animals respond flexibly to changes in reward value based on both internal and external factors (Webber et al., 2015).

Accordingly, findings have been inconsistent regarding the relationship between reinforcement magnitude and animals' response rates under single-operant schedules, showing either a positive relationship, a negative relationship, or no relationship at all (reviewed by Collier et al., 1986; Trosclair-Lasserre et al., 2008). Moreover, even under conditions of constant reward presentation, animals have been found to show reliable and systematic changes in responding in operant tasks. Such response changes may include increasing, decreasing, and bitonic functions of responding, presumably reflecting sensitisation and habituation to the sensory properties of the rewards with repeated presentation (McSweeney and Murphy, 2017, 2009, 2000).

Sudden changes in reward value may produce effects that are out of proportion to their absolute value due to animals' expectations influencing their appraisal of rewards. For example, a number of studies on rats (reviewed: Flaherty, 1999) and a few on other mammals and birds (Bentosela et al., 2009; Freidin et al., 2009; Papini, 2014) have demonstrated that when animals unexpectedly receive a lower value reward than they have received previously, they may exhibit a change in anticipatory and/or consummatory responses that is exaggerated relative to a control 'unshifted' group that have only ever received the lower value reward (Flaherty, 1999). These exaggerated behavioural reactions to a reward downshift - referred to as "successive negative contrast (SNC) effect" - are believed to reflect an aversive emotional response when animals' reward expectancies are not met (Flaherty, 1999; Cuenya et al., 2012) and may be influenced by background affective state (Burman et al., 2008).

The possibility of such effects when using food in animal training should be considered, given that varying reward quantity and/or quality may affect the subject's motivation and performance. To infer the value of a given reward to the animal, usually either 'preference tests' (also referred to as 'choice tests') or 'motivation tests' are conducted (Kirkden and Pajor, 2006). 'Preference/choice tests' present animals with alternative resources, assuming that the resource that animals choose more often, consume more of, or spend more time with is preferred (Kirkden and Pajor, 2006). Examples of preference tests include paired-stimulus preference tests (sequential presentation of different pairs of stimuli to calculate the proportion of choices for each stimulus, Fisher et al., 1992), multiple-stimulus assessments (the subject can choose one of several concurrently available stimuli (reviewed in DeLeon and Iwata, 1996; Shreve et al., 2017)) and free operant preference assessments (several stimuli are available for free interactions with all items (reviewed in Shreve et al., 2017)). One concern related to this type of tests is that subjects may have a tendency to approach an available stimulus, regardless of whether that stimulus functions as a reinforcer for another response (Fisher et al., 1992; Roscoe et al., 1999). This issue can be solved by conducting 'motivation tests', which require the animal to pay a cost of some kind (usually performing an operant response, Dawkins, 2004; Hovland et al., 2006; Mason et al., 2001, 1998; Rashotte and Smith, 1984; Smith et al., 1984), or accept loss of another resource to obtain the resource of interest (Kirkden and Pajor, 2006) - although the division is not always clear.

A relatively new protocol, the 'non-consummatory' food preference test by Thompson et al. (2016) was developed in domestic dogs based on behaviour directed at inaccessible food rewards. After the subject has sampled a small amount of each food type, the different foods are presented concurrently in such a way that they can be seen and smelled, but not accessed (Bremhorst et al., 2018; Thompson et al., 2016). The time subjects spent investigating and trying to obtain each inaccessible food type was found to correlate with proportionate consumption when the different food types were concurrently available. As a result, investigation time can be used as a proxy for relative preference (Thompson et al., 2016). The test has further demonstrated temporal consistency, indicating that it reliably measures relative food preferences in pet dogs (Thompson et al., 2016). As the test is based on dogs' natural behaviour when faced with an inaccessible food reward, it requires no pre-training, is quick to perform, and requires minimal food consumption (Thompson et al., 2016). The latter makes it advantageous in situations where habituation and/or satiation should be avoided (such as when the aim is to proceed with behavioural/cognitive testing after the preference test). Moreover, subjects may be less likely to develop side preferences, which are commonly observed in tasks consisting of repeated two-choice trials (e.g. Gácsi et al., 2009; Hare and Tomasello, 1999; Riemer et al., 2014b; Ventricelli et al., 2013).

Although the domestic dog is one of the most popular companion animals as well as used in diverse working roles, and despite great advances in positive reinforcement training in recent decades, few studies have investigated how to optimise performance motivation through the efficient use of food in this species (but see Bremhorst et al., Bremhorst et al., n.d.; Vicars et al., 2014). In the current study we were interested in both preference and motivation for different rewards in pet dogs, aiming to investigate:

(1) the effect on behaviour of differential values and unexpected changes in the quality and quantity of food rewards; and

(2) whether preference in a concurrent choice test reflected relative incentive motivation for different rewards in a single-operant task.

The first research question was based on the conflicting results of previous studies on dogs' responses (and occurrence of a successive negative contrast effect) following variation in reward quality in an instrumental eye-gaze paradigm (Bentosela et al., 2009; Riemer et al., 2016). In this task, dogs had to gaze at a human for a specified duration to earn a reward (Bentosela et al., 2009; Riemer et al., 2016). Due to the possible confounding influences of human interaction in the eye-gaze paradigm, we decided to replace eye gaze with runway running in the current study. The runway task is a classical operant task used in studies of successive negative contrast, in which animals have to traverse a runway to receive a reward at the end. Changes in running speed can typically be observed in relation to changes in reward quality or 
quantity (e.g. Binkley et al., 2014; Capaldi, 1972).

The second research question was based on the fact that preference and motivation usually, but not always converge. Neurobiologically, different substrates process 'wanting' and 'liking', or motivation and pleasure (Berridge, 2009; Smith et al., 2011). In previous behavioural experiments, some variation has been found as to whether the outcome of preference tests is reflected in motivational measures (Lee et al., 2010; Roscoe et al., 1999; Vicars et al., 2014). Additionally, while several studies have demonstrated that dogs show a preference for a larger over a smaller quantity of food (Prato-Previde et al., 2008; Riemer et al., 2014a; Ward and Smuts, 2007; Wright et al., 2012), to our knowledge it has never been investigated whether this preference also translates to increased operant motivation.

\section{Methods}

\subsection{Overview}

Dogs were trained to traverse a $20 \mathrm{~m}$ long runway to access one or several food bowls filled with either a preferred or a less preferred reward (depending on condition). After completing the training, dogs were tested in a within-subjects design, with two test sessions of ten trials taking place approximately one week apart. In a counter-balanced order, dogs received a 'shifted' session (during which reward quality or quantity was altered) and an 'unshifted' session (during which dogs received the same, less preferred, reward in all trials; see below). Two studies were conducted in parallel: In Study 1 the reward quantity was varied and in Study 2 the reward quality was varied.

\subsection{Subjects}

Twenty-eight privately owned dogs were recruited via the University of Lincoln's PetsCanDo database. However, of these, nine dogs did not complete training due to health reasons (e.g. signs of lameness, five dogs) or a lack of motivation (four subjects). These individuals were therefore excluded, leaving 19 dogs of various breeds. Study 1 (Quantity) included nine subjects ( 4 male, 5 female, age range 13-104 months, mean 56.1 months) and Study 2 (Quality) included ten subjects ( 6 male, 4 female, aged between 14 and 104 months; mean 44.6 months), with one dog participating in both studies (Supplementary Table 1). Owners were asked not to feed their dogs for four hours prior to the experiment. Apart from this, dogs were not fooddeprived, and they had water available at all times.

\subsection{Preliminary preference test}

To confirm the dogs' preferences for the predicted higher value rewards, a non-consummatory preference test following the protocol by Thompson et al. (2016) was conducted prior to runway testing. Initially dogs were allowed to sample the respective amounts of food (Study 1, quantity) or one piece of each food type (Study 2, quality). All dogs consumed all the food offered in the preliminary preference assessment. Then the predicted high and low value rewards were placed under two separate wire covers, rendering them inaccessible to the dog, while visual and olfactory cues were present. The dog was released and the time spent investigating the two covers (defined as eye gaze, sniffing and licking behaviours, pawing at the covers, and vocalizations directed to the bowls/covers) within a one-minute period was recorded, using investigation time as a proxy for relative preference (Thompson et al., 2016). Reliability between the first and third author was established for ten randomly selected dogs. The first and third author had perfect agreement regarding the designation of the favoured reward and had agreements of Cronbach's $\alpha=0.848$ for investigation directed at the right cover and $\alpha=0.781$ for investigation directed at the right cover.

\subsection{Runway task-reward conditions}

In Study 1 (Quantity) the higher value reward was presented as a row of five identical blue food bowls placed $30 \mathrm{~cm}$ behind the finishing point of the runway, each bowl containing one piece of dry food, while the low value reward was just one blue bowl containing a single piece of dry food. In addition to subjects exhibiting a preference for the larger quantity in the preliminary non-consummatory preference test (Supplementary Table 2), several previous studies have demonstrated dogs' ablity to discriminate between different quantities of food and to select the larger one (to be consumed) in concurrent choice tests (PratoPrevide et al., 2008; Riemer et al., 2014a; Ward and Smuts, 2007; Wright et al., 2012). In the case of Wright et al. (2012) and Riemer et al. (2014a,b), the ratio was even lower than in the current study at 1:3.

In Study 2 (Quality), single pieces of either sausage or dry food were presented at the end of the runway in either a black or white bowl, since sausage has been shown to be preferred to dry food in dogs (MarshallPescini et al., 2011; Riemer et al., 2016), and as confirmed in our own preliminary preference test (Supplementary Table 3). Colours of bowls were counter-balanced between subjects, with half the subjects receiving sausage in a black bowl and the other half in a white bowl, and vice versa for dry food. Visual signalling of the reward type in both studies, as occurs in tests of consummatory SNC when visual/olfactory cues are immediately present (e.g. Pellegrini and Mustaca, 2000), was intended to highlight the change in reward value prior to consumption. Note, however, that prior cueing of a change in reward value is not a precondition for animals to respond to changes in reward value during repeated trials, and its absence does not prevent SNC effects from occurring (see reviews on SNC in Flaherty, 1999; Papini, 2003).

\subsection{Runway task-training}

Testing was performed by two female experimenters (hereafter, 'handler' and 'experimenter'), with the dogs' owners either absent or watching through one-way mirrors from outside the test room. The runway task was performed in a dedicated test area measuring $6.5 \mathrm{~m} \times 23 \mathrm{~m}$. The starting point and the finishing point of the 'runway' were marked on the floor by white tape, $20 \mathrm{~m}$ apart. Following preference testing, dogs were given ten training trials during which they learned to run to a food bowl (or several bowls) placed behind the finishing line. During the initial two trials, the dog, held on lead by the handler, was positioned at the finish line. The experimenter entered the room, placed a bowl with one piece of food at the finishing point and left the room. After her exit, the handler gave the dog a release cue "take it" and allowed the dog to eat the food. The experimenter returned to the room to collect the bowl, re-filled it outside the test room, and started the next trial.

This procedure was followed for the subsequent eight training trials, whereby the distance of the dog from the finishing line was increased to two metres during trials 3 and 4, to $5 \mathrm{~m}$ during trials 5 and 6 , to $10 \mathrm{~m}$ during trials 7 and 8 , and to $20 \mathrm{~m}$ during trials 9 and 10 . The dog was given a maximum of one minute from being released to consume the food. If the dog did not eat the food within this time period, the handler collected it and returned to the starting point for the next trial. The type of reward (i.e. quantity/quality) used depended on the study (as described above). Dogs that were due to be exposed to the unshifted condition first received the low value reward in all ten training trials, whereas dogs due to be exposed to the shifted condition first received the low value reward during training trials $1-5$ and the high value reward during training trials 6-10 so that all dogs ended training on the same value reward that they were due to experience in their first test trial.

\subsection{Runway task-testing}

Testing commenced immediately upon completion of the training 


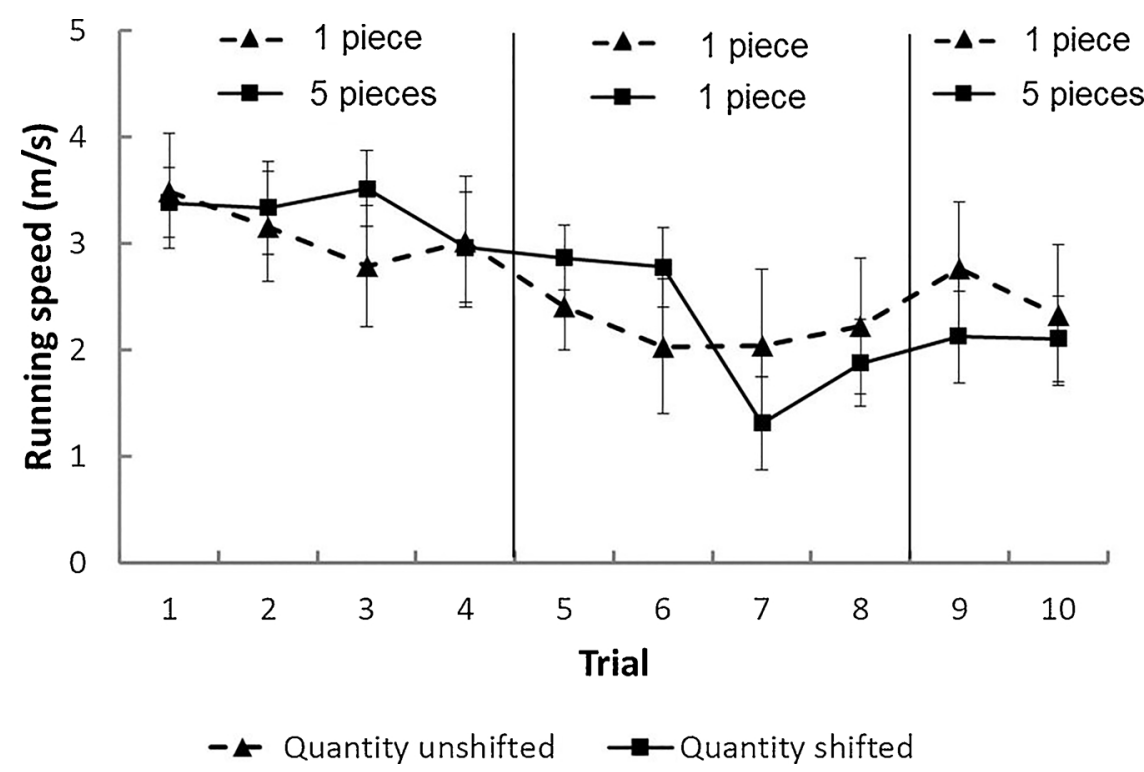

Fig. 1. Mean running speed \pm SEM during the unshifted and shifted treatments of the quantity study.

stage. The handler positioned the dog on the start line. The experimenter entered the room, placed the filled food bowl(s) on the marker (s) behind the finish line and then left the room. Ten seconds after the experimenter's exit, the handler unclipped the dogs' lead and gave the release cue as in the training trials. Observing the dog from outside the test room through one-way mirrors, the experimenter measured the duration until the dog reached the finish line (both front feet having crossed the line) from the point of release.

When the dog had eaten all food and lifted its head from the bowl (s), or one minute after release (whichever occurred earlier), the handler collected the dog and returned it to the start line. In order to control for fatigue potentially affecting running speed in subsequent trials, if the dog had not reached the finish line at the time s/he was collected by the handler, the handler first walked the dog to the finish point (not allowing the dog to eat the food from the bowl) before returning to the start line to control for distance travelled by each dog. Testing then proceeded with the next trial.

Ten test trials were conducted per session, with a two-minute break between trials during which the dogs stayed outside of the test room. While dogs in the unshifted condition received the low value reward in all trials, dogs in the shifted condition received the high value reward during the first four trials (pre-shift), followed by the low value reward in trials 5-8 (post-shift), and the high value reward again in the final trials, 9 and 10 (re-shift).

\subsection{Statistical analyses}

Statistical analyses were performed with $\mathrm{R}$ version 3.3 .3 ( $\mathrm{R}$ Development Core Team 2017), with the alpha value set at the 0.05 level. All analyses involved two-tailed tests. As data met the requirements for parametric analysis, paired $t$-tests were calculated to assess food preferences at the within-subject level.

Runway data were analysed separately for the pre-shift, post-shift and re-shift phases. Running speed was calculated from the latencies, with dogs that failed to approach the food bowl within one minute receiving a value of zero. Differences in dogs' running speed according to treatment (shifted/unshifted) were analysed with linear mixed-effect models (function lme from the package nlme). Treatment, trial and the treatment*trial interaction were included as fixed factors and ID nested in treatment order (i.e. whether dogs received the shifted or the unshifted condition first) was included as a random factor. An inspection of the model residuals indicated that all data were suitable for parametric testing with the exception of the pre-shift phase of the quality condition, where data met the necessary assumptions following square-root transformation. Akaike Information Criterion was used to select the best model (lowest AIC) for each phase.

\section{Results}

\subsection{Non-consummatory food preference test}

\subsubsection{Study 1 - Quantity}

Dogs in the quantity preference test spent on average $9.67 \pm 2.56 \mathrm{~s}$ investigating the larger quantity of food and $4.83 \pm 1.6 \mathrm{~s}$ investigating the smaller quantity, demonstrating a significant preference for the 5 pieces over the 1 piece of food (paired $t$-test, $t=3.674, \mathrm{~N}=9$, $\mathrm{p}=0.006$; see Supplementary Table 2 for individual results).

\subsubsection{Study 2 - Quality}

Dogs in the quality preference test also exhibited a significant preference by spending on average $22.83 \pm 5.71 \mathrm{~s}$ investigating the sausage, compared to $9.33 \pm 1.43 \mathrm{~s}$ investigating the dry food (paired $t$ test, $\mathrm{t}=6.087, \mathrm{~N}=10, \mathrm{p}<0.001$; see Supplementary Table 3 for individual results).

\subsection{Runway performance}

\subsubsection{Study 1- Quantity}

As shown in Fig. 1, dogs' running speed did not differ significantly between conditions (shifted/unshifted) in any of the three phases (preshift, post-shift and re-shift) of the quantity treatment. To see data at an individual level, please refer to Supplementary Tables 4 and 5. The best model for the pre-shift phase of the quantity condition included only Shift condition, although no significant difference in running speed was observed between the low and the high quantity of dry food $\left(\mathrm{F}_{1,62}=1.243, \mathrm{p}=0.269\right)$.

For the post-shift phase, a model including Shift condition $\left(\mathrm{F}_{1,61}=1.711, \mathrm{p}=0.196\right)$ and Trial $\left(\mathrm{F}_{1,61}=3.801, \mathrm{p}=0.056\right)$ and $\mathrm{a}$ model including Trial only $\left(\mathrm{F}_{1,61}=3.759, \mathrm{p}=0.057\right)$ were within two AIC units from each other, indicating that there was no significant effect of Shift condition on running speed, but a trend towards an effect of trial.

For the re-shift phase, the best model included Shift condition only $\left(F_{1,26}=0.070, p=0.793\right)$, which had no significant effect on running 


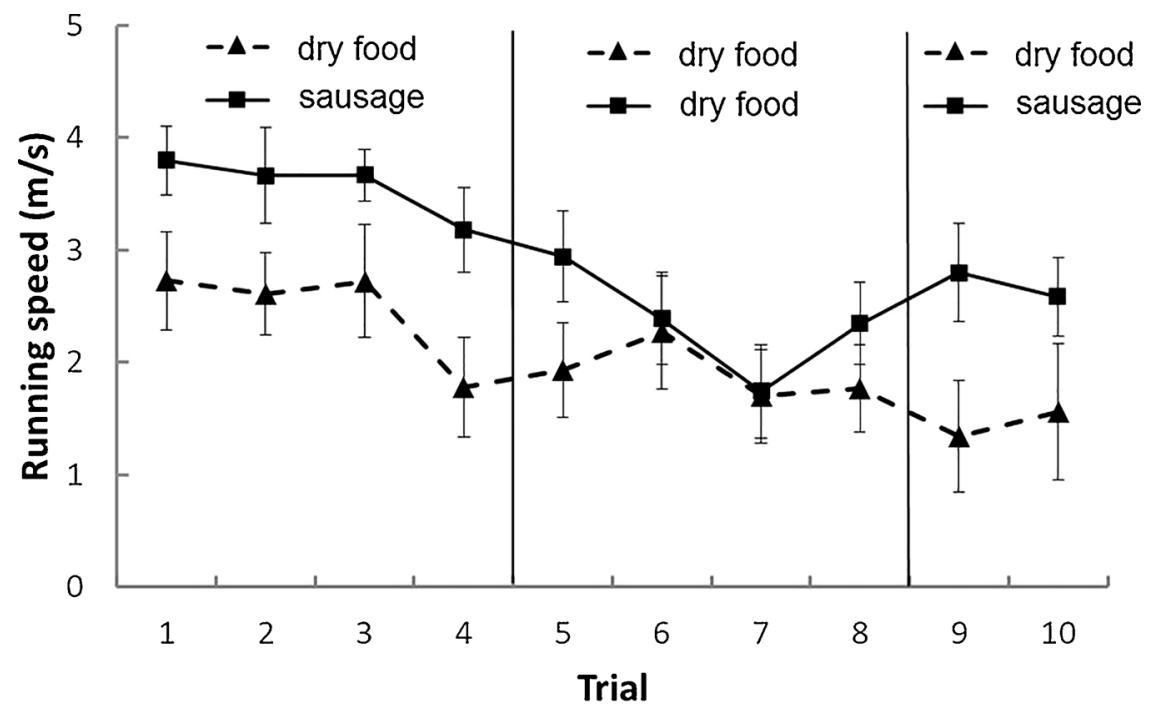

- Quality Unshifted $\rightarrow$ Quality Shifted

Fig 2. Mean running speed \pm SEM during the unshifted and shifted treatments of the quality study.

speed.

\subsubsection{Study 2- Quality}

Unlike in the quantity study, dogs' performance differed between shift conditions in the quality study 2 (Fig. 2). To see data at an individual level, please refer to Supplementary Tables 6 and 7. The best model for the pre-shift phase of the quality condition included Shift condition $\left(\mathrm{F}_{1,68}=21.708 \mathrm{p}<0.001\right)$ and Trial $\left(\mathrm{F}_{1,68}=4.168\right.$, $\mathrm{p}=0.045$ ), with no interaction. Dogs ran significantly faster when the reward was sausage (high quality) than when the reward was dry food (low quality). Despite the marginally significant effect of trial in the model, Tukey's post-hoc test did not indicate any difference in the pairwise comparisons of the four trials (all $\mathrm{p}>0.2$ ).

In post-shift trials, when dogs received dry food in both conditions, the best model included Shift condition $\left(\mathrm{F}_{1,68}=4.183 \mathrm{p}=0.045\right)$ and Trial, although the effect of trial was not significant $\left(F_{1,68}=3.295\right.$, $\mathrm{p}=0.074$ ). Dogs' running speed was still faster in the shifted condition than in the unshifted condition.

For the re-shift trials, the best model included an effect of Shift condition only $\left(F_{1,29}=9.999, p=0.0037\right)$, with dogs running faster towards the sausage than towards the dry food.

\section{Discussion}

Although the dogs exhibited a significant preference for both the higher food quantity and the higher food quality in the preliminary concurrent choice test, this preference was not found to be consistently related to motivation (as measured by strength of goal-directed behaviour, in this case running speed) in the operant runway task. While the dogs did alter their behaviour in response to variation in food quality by running significantly faster for the higher quality than for the lower quality food, running speed did not differ significantly between the two reward quantities. Thus, the greater food quantity did not enhance incentive motivation, or goal-directed behaviour (c.f. Depue and Collins, 1999), relative to the lower food quantity despite our subjects' clear preference for the larger food amount in the initial choice test, and despite evidence from previous studies that dogs preferably select the larger reinforcer quantity with ratios of 1:3 (Riemer et al., 2014a; Wright et al., 2012), 1:5 (Ward and Smuts, 2007) and 1:8 (PratoPrevide et al., 2008), respectively, in choice tests. This finding appears to contradict the traditional assumption that a greater magnitude of reinforcement entails a greater response strength or should be related to greater incentive motivation (reviewed by Collier et al., 1986; Flaherty, 1999). Thus, the current study adds to the inconsistent results from previous studies investigating the relationship between operant responding and the magnitude of contingent reinforcers, which ranged from positive relationships, negative relationships, to no relationship at all (reviewed by Trosclair-Lasserre et al., 2008).

One explanation for this apparent discrepancy is that only responses under concurrent schedules, but not under single-operant schedules, appear to be reliably related to the magnitude of rewards (reviewed by Bonem and Crossman, 1988; Trosclair-Lasserre et al., 2008). There is also some evidence that a larger range of reward magnitudes produces more magnitude-dependent responding than when only a small range is used (reviewed by Bonem and Crossman, 1988) and, regarding the special case of successive negative contrast, stronger effects are observed with a greater reward disparity (Peters and McHose, 1974; Flaherty, 1999; Rosas et al., 2007). Thus, although studies have found magnitude effects in operant responding with quantity differences of 1:3 or 1:4 in dogs (Roll et al., 1995; Melville and Weatherly, 1996), the reinforcer disparity of 1 vs. 5 pieces of the same food type in our study may not have been sufficiently great for magnitude-dependent effects to occur within the context of this single-operant paradigm. It is thus conceivable that stronger effects would have emerged had we used either a larger food quantity disparity for the low value food or varied quantities of the higher value reward.

Unlike for quantity, dogs' operant runway behaviour in the quality study confirmed their initial preference for the high over the lower value reward: in both the pre-shift and re-shift phases subjects ran significantly faster towards the food bowl when rewarded with sausage compared to when the reward was dry food. Perhaps the disparity in reward value was more salient for the different food types because they varied in a number of features (for example, in the relative amounts of nutritional constituents, and thus in the key perceptual modalities of vision, olfaction and taste, e.g. Hollmann et al., 2013) when compared to a single food type that varied in quantity. Calorific content cannot account for the differences observed between the high value quantity and the high value quality condition, since the energy density of the dry food is considerably higher ( $362 \mathrm{kcal} / 100 \mathrm{~g}$ ) than that of the sausage ( $262 \mathrm{kcal} / 100 \mathrm{~g}$ ). This implies that it was the difference in palatability and not energy content that affected dogs' choices. Moreover, although both higher quantity and higher quality were preferred in the initial 
choice test, there was a slightly 'stronger' preference for the high quality reward as well as more total time spent investigating the two food types (high quantity: $67 \%$ of $14.5 \mathrm{~s}$; high quality: $71 \%$ of $32.2 \mathrm{~s}$ ) that could have translated into greater reinforcer effectiveness (e.g. Piazza et al., 1996).

It is notable that dogs experiencing the shifted treatment continued to run faster following a downshift from the high quality to the low quality reward than when they had received the low value reward in all trials - similar as has been found in a previous study in which reward value was altered (Riemer et al., 2016). It is possible that reinforcer efficiency of the dry food in the unshifted treatment decreased due to the process of habituation, whereas in the shifted condition, the dry food received in the post-shift phase was still novel - and therefore potentially more reinforcing. Thus it has been demonstrated that dogs will habituate to specific food types with repeated presentation and show an increased preference for different food rewards as the session progresses (Bremhorst et al., Bremhorst et al., n.d.).

Although the obtained result is contrary to the predictions of successive negative contrast, another possibility is that dogs that were used to the high value reward had more positive expectations, perhaps having developed a more positive (classically conditioned) association with the task (or the food bowl location) during training with highvalue rewards. It is likely that performance would have declined if a higher number of trials had been conducted following the downshift. Thus, there was a trend towards a significant effect of Trial, with dogs running fastest in the first post-shift trial compared to the other three trials. Generally, although running speed of dogs in the quality condition increased again during re-shift compared to the post-shift phase (but not to the level of the pre-shift phase), running speed tended to decrease across the ten test trials across all conditions, perhaps reflecting fatigue, satiation or habituation.

To date, a few studies have investigated the effects of varying quantity and what they refer to as 'quality' (sucrose content of food or liquid rewards) on runway performance, maze performance or lever pressing in rodents. However, we are not aware of a study that included both rewards differing in quantity and truly qualitatively different rewards (i.e. using different food types), as in the current study. Nonetheless, some of these previous studies confirm that under some circumstances, animals respond more strongly to variation in quality (sucrose concentration) compared to variation in quantity (but see Taylor, 1977). For example, rats tested in an operant bar-pressing task reacted sensitively to qualitative but not quantitative differences, with rate of responding being related to sucrose content of the pellet, but not number of pellets obtained (Schaeffer and Hanna, 1966). In another study employing a bar-pressing task in rats, acquisition performance was related to both quantity and sucrose concentration of a liquid reward, whereas only concentration affected behaviour during extinction (Marx and Tombaugh, 1970).

Neither in the quantity nor the quality study did we observe a successive negative contrast effect in the dogs when reward values were changed and, similarly, there is only limited evidence of the occurrence of SNC effects in this species. Although Bentosela et al. (2009) reported a SNC effect in consumption in dogs, this could not be replicated in a later study (Riemer et al., 2016). Thus, based on the currently available data, dogs appear to be somewhat less sensitive to reward loss than other mammalian species tested, most notably the laboratory rat, and this could be explained by both lifetime experiences and artificial selection. Firstly, it is a possibility that through selecting dogs for high trainability, there has been a parallel selection for reduced sensitivity to reward loss. Secondly, pet dogs generally live in highly enriched environments (regarding both social and environmental experiences), which has been suggested to be associated with a more positive affective state and subsequently lower sensitivity to negative events such as reward loss (e.g. Burman et al., 2008). Thirdly, it is possible that our subjects had previous experience of receiving intermittent reinforcement, such as during daily training experiences with their owners, possibly making them more resistant to subsequent reward omission or reduction (Mellgren, 1972; Capaldi and Singh, 1973; Flaherty, 1999; Pellegrini et al., 2004; Cuenya et al., 2012).

Even if the results of the current study should be interpreted with some caution given the relatively low sample sizes, our findings suggest that, at least in non-food deprived dogs participating in a single-operant runway task, a food reward of higher quality represents a more effective reinforcer than a greater quantity of a less favoured food item, all other things being equal. While another factor to consider is that of rewardspecific habituation (Bremhorst et al., Bremhorst et al., n.d), on this basis it can be recommended to deliver higher quality rewards, rather than a greater quantity of a lower value reward, in order to optimise dogs' motivation in operant tasks.

\section{Compliance with ethical standards}

This work followed the Association for the Study of Animal Behaviour (ASAB) guidelines for the use of animals in research and was approved locally by the Research Ethics Committee of the School of Life Sciences at the University of Lincoln. Dog owners gave written consent for their dogs to be included in the study. The authors declare that they have no conflict of interest.

\section{Acknowledgements}

This research was supported by the Biotechnology and Biological Sciences Research Council Grant BB/J00703X/1 awarded to Oliver H. P. Burman. Many thanks to the dog owners for volunteering their dogs, Sian Ryan for her contribution to pilot testing, and to Jessica Waby, Penny Ingleton, Magalie Bertrand and Maria Cecília Alvim Faria for their assistance with data collection.

\section{Appendix A. Supplementary data}

Supplementary data associated with this article can be found, in the online version, at https://doi.org/10.1016/j.applanim.2018.05.016.

\section{References}

Arhant, C., Bubna-Littitz, H., Bartels, A., Futschik, A., Troxler, J., 2010. Behaviour of smaller and larger dogs: effects of training methods, inconsistency of owner behaviour and level of engagement in activities with the dog. Appl. Anim. Behav. Sci. 123, 131-142.

Bentosela, M., Jakovcevic, A., Elgier, A.M., Mustaca, A.E., Papini, M.R., 2009. Incentive contrast in domestic dogs (Canis familiaris). J. Comp. Psychol. 123, 125-130.

Berridge, K.C., Robinson, T.E., 1995. The mind of an addicted brain: neural sensitization of wanting versus liking. Cur. Dir. Psychol. Sci. 4 (4), 71-76.

Berridge, K.C., 2000. Reward learning: reinforcement, incentives, and expectations. Psychol. Learn. Motiv. 40, 223-278.

Berridge, K.C., 2009. Liking and wanting food rewards: brain substrates and roles in eating disorders. Physiol. Behav. 97, 537-550.

Binkley, K.A., Webber, E.S., Powers, D.D., Cromwell, H.C., 2014. Emotion and relative reward processing: an investigation on instrumental successive negative contrast and ultrasonic vocalizations in the rat. Behav. Processes 107, 167-174.

Blackwell, E., Twells, C., Seawright, a, Casey, R., 2008. The relationship between training methods and the occurrence of behavior problems, as reported by owners, in a population of domestic dogs. J. Vet. Behav. Clin. Appl. Res. 3, 207-217. http://dx.doi. org/10.1016/j.jveb.2007.10.008.

Bonem, M., Crossman, E.K., 1988. Elucidating the effects of reinforcement magnitude. Psychol. Bull. 104, 348

Boyer, W.N., Swank, P.R., 1980. Positive and negative simultaneous and successive contrast effects following shifts in qualitative reinforcement. J. Gen. Psychol. 102, $3-12$.

Bremhorst, A., Bütler, S., Würbel, H., Riemer, S., 2018. Incentive motivation in pet dogspreference for constant vs varied reward types. Sci. Rep. 8, 9756.

Burman, O.H.P., Parker, R.M.A., Paul, E.S., Mendl, M., 2008. Sensitivity to reward loss as an indicator of animal emotion and welfare. Biol. Lett. 4, 330-333.

Capaldi, E.D., Singh, R., 1973. Percentage body weight and the successive negative contrast effect in rats. Learn. Motiv. 4, 405-416.

Capaldi, E.J., 1972. Successive negative contrast effect: intertrial interval, type of shift, and four sources of generalization decrement. J. Exp. Psychol. 96, 433.

Collier, G.H., Johnson, D.F., Hill, W.L., Kaufman, L.W., 1986. The economics of the law of effect. J. Exp. Anal. Behav, 46, 113

Crespi, L.P., 1942. Quantitative variation of incentive and performance in the white rat. 
Am. J. Psychol. 467-517.

Cuenya, L., Sabariego, M., Donaire, R., Fernández-Teruel, A., Tobeña, A., Gómez, M.J., Mustaca, A., Torres, C., 2012. The effect of partial reinforcement on instrumental successive negative contrast in inbred Roman High-(RHA-I) and Low-(RLA-I) Avoidance rats. Physiol. Behav. 105, 1112-1116.

Dawkins, M.S., 2004. Using behaviour to assess animal welfare. Anim. Welf. 13, S3-S8.

DeLeon, I.G., Iwata, B.A., 1996. Evaluation of a multiple-stimulus presentation format for assessing reinforcer preferences. J. Appl. Behav. Anal. 29, 519-533.

Deldalle, S., Gaunet, F., 2014. Effects of 2 training methods on stress-related behaviors of the dog (Canis familiaris) and on the dog-owner relationship. J. Vet. Behav. Clin. Appl. Res. 9, 58-65.

Depue, R.A., Collins, P.F., 1999. Neurobiology of the structure of personality: dopamine, facilitation of incentive motivation, and extraversion. Behav. Brain Sci. 22, 491-517.

Desmond, T., Laule, G., 1994. Use of positive reinforcement training in the management of species. Zoo Biol 13, 471-477.

Elliott, M.H., 1928. The effect of change of reward on the maze performance of rats. Univ. Calif. Publ. Psychol.

Fisher, W., Piazza, C.C., Bowman, L.G., Hagopian, L.P., Owens, J.C., Slevin, I., 1992. A comparison of two approaches for identifying reinforcers for persons with severe and profound disabilities. J. Appl. Behav. Anal. 25, 491-498.

Flaherty, C.F., 1999. Incentive Relativity. Cambridge University Press.

Freidin, E., Cuello, M.I., Kacelnik, A., 2009. Successive negative contrast in a bird: starlings' behaviour after unpredictable negative changes in food quality. Anim. Behav 77, 857-865.

Fukuzawa, M., Hayashi, N., 2013. Comparison of 3 different reinforcements of learning in dogs (Canis familiaris). J. Vet. Behav. Clin. Appl. Res. 8, 221-224.

Gácsi, M., Kara, E., Belényi, B., Topál, J., Miklósi, Á., 2009. The effect of development and individual differences in pointing comprehension of dogs. Anim. Cogn. 12, 471-479.

Gaalema, D.E., Perdue, B.M., Kelling, A.S., 2011. Food preference, keeper ratings, and reinforcer effectiveness in exotic animals: the value of systematic testing. J. Appl. Anim. Welf. Sci. 14, 33-41.

Goomas, D.T., 1981. Multiple shifts in magnitude of reward. Psychol. Rep. 49, 335-338.

Hare, B., Tomasello, M., 1999. Domestic dogs (Canis familiaris) use human and conspecific social cues to locate hidden food. J. Comp. Psychol. 113, 173.

Haverbeke, A., Laporte, B., Depiereux, E., Giffroy, J.-M., Diederich, C., 2008. Training methods of military dog handlers and their effects on the team's performances. Appl. Anim. Behav. Sci. 113, 110-122.

Haverbeke, A., Rzepa, C., Depiereux, E., Deroo, J., Giffroy, J.-M., Diederich, C., 2010. Assessing efficiency of a Human Familiarisation and Training Programme on fearfulness and aggressiveness of military dogs. Appl. Anim. Behav. Sci. 123, 143-149.

Herrnstein, R.J., 1970. On the law of effect. J. Exp. Anal. Behav. 13, 243-266.

Herron, M.E., Shofer, F.S., Reisner, I.R., 2009. Survey of the use and outcome of confrontational and non-confrontational training methods in client-owned dogs showing undesired behaviors. Appl. Anim. Behav. Sci. 117, 47-54.

Hiby, E.F., Rooney, N.J., Bradshaw, J.W.S., 2004. Dog training methods: their use, effectiveness and interaction with behaviour and welfare. Anim. Welf. 13, 63-70.

Hollmann, M., Pleger, B., Villringer, A., Horstmann, A., 2013. Brain imaging in the context of food perception and eating. Curr. Opin. Lipidol. 24, 18-24.

Hovland, A.L., Mason, G., Bøe, K.E., Steinheim, G., Bakken, M., 2006. Evaluation of the maximum price paidas an index of motivational strength for farmed silver foxes (Vulpes vulpes). Appl. Anim. Behav. Sci. 100, 258-279.

Hutt, P.J., 1954. Rate of bar pressing as a function of quality and quantity of food reward. J. Comp. Physiol. Psychol. 47, 235.

Killeen, P.R., Jacobs, K.W., 2016. Coal is not black, snow is not white, food is not a reinforcer: the roles of affordances and dispositions in the analysis of behavior. Behav. Anal. 1-22.

Kirkden, R.D., Pajor, E.A., 2006. Using preference, motivation and aversion tests to ask scientific questions about animals' feelings. Appl. Anim. Behav. Sci. 100, 29-47.

Lee, M.S.H., Yu, C.T., Martin, T.L., Martin, G.L., 2010. On the relation between reinforcer efficacy and preference. J. Appl. Behav. Anal. 43, 95-100.

Lowe, C.F., Davey, G.C.L., Harzem, P., 1974. Effects of reinforcement magnitude on interval and ratio schedules. J. Exp. Anal. Behav, 22, 553-560.

Manteuffel, G., Langbein, J., Puppe, B., et al., 2009. From operant learning to cognitive enrichment in farm animal housing: bases and applicability. Anim. Welf. 18, 87-95.

Marshall-Pescini, S., Prato-Previde, E., Valsecchi, P., 2011. Are dogs (Canis familiaris) misled more by their owners than by strangers in a food choice task? Anim. Cogn. 14, 137-142.

Marx, M.H., Tombaugh, T.N., 1970. Acquisition and extinction of an instrumental response as a function of quality and quantity of reinforcement. Psychol. Rec. 20, 297-303.

Mason, G.J., McFarland, D., Garner, J., 1998. A demanding task: assessing the needs of captive animals. Anim. Behav. 55, 1071-1075.

Mason, G.J., Cooper, J., Clarebrough, C., 2001. Frustrations of fur-farmed mink. Nature 410, 35-36.

Maxwell, F.R., Calef, R.S., Murray, D.W., Shepard, J.C., Norville, R.A., 1976. Positive and negative successive contrast effects following multiple shifts in reward magnitude under high drive and immediate reinforcement. Anim. Learn. Behav. 4, 480-484.

McSweeney, F.K., Murphy, E.S., 2000. Criticisms of the satiety hypothesis as an explanation for within-session decreases in responding. J. Exp. Anal. Behav. 74, 347-361.

McSweeney, F.K., Murphy, E.S., 2009. Sensitization and habituation regulate reinforcer effectiveness. Neurobiol. Learn. Mem. 92, 189-198.

McSweeney, F.K., Murphy, E.S., 2017. Understanding operant behavior: still experimental analysis of the three-term contingency. Behav. Anal. 1-9.

Mellgren, R.L., 1972. Positive and negative contrast effects using delayed reinforcement. Learn. Motiv. 3, 185-193.
Melville, C.L., Weatherly, J.N., 1996. Within-session patterns of responding when rats run in a T-maze. Behav. Processes 38, 89-102.

Miller, H.L., 1976. Matching-based hedonic scaling in the pigeon. J. Exp. Anal. Behav. 26 335-347.

Papini, M.R., 2003. Comparative psychology of surprising nonreward. Brain Behav. Evol. 62, 83-95.

Papini, M.R., 2014. Diversity of adjustments to reward downshifts in vertebrates. Int. J. Comp. Psychol. 27.

Pellegrini, S., Mustaca, A., 2000. Consummatory successive negative contrast with solid food. Learn. Motiv. 31, 200-209.

Pellegrini, S., Muzio, R.N., Mustaca, A.E., Papini, M.R., 2004. Successive negative contrast after partial reinforcement in the consummatory behavior of rats. Learn. Motiv. 35, 303-321.

Perlman, J.E., Bloomsmith, M.A., Whittaker, M.A., McMillan, J.L., Minier, D.E., McCowan, B., 2012. Implementing positive reinforcement animal training programs at primate laboratories. Appl. Anim. Behav. Sci. 137, 114-126.

Peters, D.P., McHose, J.H., 1974. Effects of varied preshift reward magnitude on successive negative contrast effects in rats. J. Comp. Physiol. Psychol. 86, 85.

Piazza, C.C., Fisher, W.W., Hagopian, L.P., Bowman, L.G., Toole, L., 1996. Using a choice assessment to predict reinforcer effectiveness. J. Appl. Behav. Anal. 29, 1-9.

Prato-Previde, E., Marshall-Pescini, S., Valsecchi, P., 2008. Is your choice my choice? The owners' effect on pet dogs' (Canis lupus familiaris) performance in a food choice task. Anim. Cogn. 11, 167-174.

Rashotte, M.E., Smith, J.C., 1984. Operant conditioning methodology in the assessment of food preferences: introductory comments. Neurosci. Biobehav. Rev. 8, 211-215.

Rashotte, M.E., 1979. Reward training: contrast effects. Animal Learning. Springer, pp. 195-239.

Riemer, S., Mills, D.S., Wright, H., 2014a. Impulsive for life? The nature of long-term impulsivity in domestic dogs. Anim. Cogn. 17, 815-819.

Riemer, S., Müller, C., Range, F., Huber, L., 2014b. Dogs (Canis familiaris) can learn to attend to connectivity in string pulling tasks. J. Comp. Psychol. 128, 31.

Riemer, S., Ellis, S.L.H., Ryan, S., Thompson, H., Burman, O.H.P., 2016. A reappraisal of successive negative contrast in two populations of domestic dogs. Anim. Cogn. 19, 471-481. http://dx.doi.org/10.1007/s10071-015-0947-0.

Roll, J.M., McSweeney, F.K., Johnson, K.S., Weatherly, J.N., 1995. Satiety contributes little to within-session decreases in responding. Learn. Motiv. 26, 323-341.

Rosas, J.M., Callejas-Aguilera, J.E., Escarabajal, M., Gómez, M., de la Torre, L., Agüero, Á., Fernández-Teruel, A., Torres, C., 2007. Successive negative contrast effect in instrumental runway behaviour: a study with Roman high-(RHA) and Roman low(RLA) avoidance rats. Behav. Brain Res. 185, 1-8.

Roscoe, E.M., Iwata, B.A., Kahng, S., 1999. Relative versus absolute reinforcement effects: implications for preference assessments. J. Appl. Behav. Anal. 32, 479-493.

Schaeffer, R.W., Hanna, B., 1966. Effects of quality and quantity of reinforcement upon response rate in acquisition and extinction. Psychol. Rep. 18, 819-829.

Schilder, M.B.H., van der Borg, J.A.M., 2004. Training dogs with help of the shock collar: short and long term behavioural effects. Appl. Anim. Behav. Sci. 85, 319-334.

Schultz, W., Dayan, P., Montague, P.R., 1997. A neural substrate of prediction and reward. Science 275, 1593-1599.

Schultz, W., 2015. Neuronal reward and decision signals: from theories to data. Physiol Rev. 95, 853-951. http://dx.doi.org/10.1152/physrev.00023.2014.

Shreve, K.R.V., Mehrkam, L.R., Udell, M.A.R., 2017. Social interaction, food, scent or toys? A formal assessment of domestic pet and shelter cat (Felis silvestris catus) preferences. Behav. Processes 141, 322-328.

Smith, J.C., Rashotte, M.E., Austin, T., Griffin, R.W., 1984. Fine-grained measures of dogs' eating behavior in single-pan and two-pan tests. Neurosci. Biobehav. Rev. 8, 243-251.

Smith, K.S., Berridge, K.C., Aldridge, J.W., 2011. Disentangling pleasure from incentive salience and learning signals in brain reward circuitry. Proc. Natl. Acad. Sci. 108, E255-E264.

Stephens, D.N., Duka, T., Crombag, H.S., Cunningham, C.L., Heilig, M., Crabbe, J.C., 2010. Reward sensitivity: issues of measurement, and achieving consilience between human and animal phenotypes. Addict. Biol. 15, 146-168. http://dx.doi.org/10. 1111/j.1369-1600.2009.00193.x.

Taylor, C., 1977. Covariation of quantity and quality of the reinforcer in rats. J. Gen. Psychol. 97, 117-130.

Thompson, H., Riemer, S., Ellis, S., Burman, O., 2016. Behaviour directed towards in accessible food predicts consumption-a novel way of assessing food preference. Appl. Anim. Behav. Sci. 178, 111-117.

Tinklepaugh, O.L., 1928. An experimental study of representative factors in monkeys. J. Comp. Psychol. 8, 197-236.

Trosclair-Lasserre, N.M., Lerman, D.C., Call, N.A., Addison, L.R., Kodak, T., 2008. Reinforcement magnitude: an evaluation of preference and reinforcer efficacy. J. Appl. Behav. Anal. 41, 203-220.

Ventricelli, M., Focaroli, V., De Petrillo, F., Macchitella, L., Paglieri, F., Addessi, E., 2013. How capuchin monkeys (Cebus apella) behaviorally cope with increasing delay in a self-control task. Behav. Processes 100, 146-152.

Vicars, S.M., Miguel, C.F., Sobie, J.L., 2014. Assessing preference and reinforcer effectiveness in dogs. Behav. Processes 103, 75-83.

Ward, C., Smuts, B.B., 2007. Quantity-based judgments in the domestic dog (Canis lupus familiaris). Anim. Cogn. 10, 71-80.

Webber, E.S., Chambers, N.E., Kostek, J.A., Mankin, D.E., Cromwell, H.C., 2015. Relative reward effects on operant behavior: incentive contrast, induction and variety effects. Behav, Processes 116, 87-99.

Wright, H.F., Mills, D.S., Pollux, P.M.J., 2012. Behavioural and physiological correlates of impulsivity in the domestic dog (Canis familiaris). Physiol. Behav. 105, 676-682. 